\title{
Comparison between intravenous and oral postoperative adjuvant immunochemotherapy in patients with stage II colorectal cancer
}

\author{
ISAO ITO $^{1}$, MASAYA MUKAI ${ }^{2}$, HIROMI NINOMIYA ${ }^{1}$, KYOKO KISHIMA $^{2}$, KAZUTOSHI TSUCHIYA ${ }^{3}$, \\ TAKAYUKI TAJIMA ${ }^{2}$, YASUHISA OIDA ${ }^{4}$, MASATO NAKAMURA $^{5}$ and HIROYASU MAKUUCHI ${ }^{4}$ \\ ${ }^{1}$ Tokai University Oiso Hospital, Department of Surgery, Gakyou 21-1, Oiso, Kanagawa 259-0198; \\ ${ }^{2}$ Tokai University Hachioji Hospital, Department of Surgery, Ishikawa-cho 1838, Hachioji, Tokyo 192-0032; \\ ${ }^{3}$ Tokai University Oiso Hospital, Department of Endoscopy, Gakyou 21-1, Oiso, Kanagawa 259-0198; \\ ${ }^{4}$ Tokai University School of Medicine, Department of Surgery, Bohseidai, Isehara, Kanagawa 259-1193; \\ ${ }^{5}$ Tokai University Hachioji Hospital, Department of Pathology, Ishikawa-cho 1838, Hachioji, Tokyo 192-0032, Japan
}

Received November 27, 2007; Accepted March 3, 2008

DOI: $10.3892 /$ or_00000128

\begin{abstract}
The present study was designed to retrospectively examine the efficacy of postoperative adjuvant chemotherapy in 107 patients with stage II primary colorectal cancer who underwent curative resection. The chemotherapy regimen was intravenous $5 \mathrm{FU} / \mathrm{LV}$ in 30 patients (FL-IV group) and oral UFT/PSK in 77 patients (oral group). There were no significant differences between the FL-IV and the oral group with respect to the 3-year relapse-free survival rate, 5-year relapse-free survival rate, and 5-year overall survival rate, which were 82.4 vs. $83.0 \%(p=0.8546), 78.8$ vs. $80.0 \%$ $(\mathrm{p}=0.756)$, and 81.6 vs. $92.8 \%(\mathrm{p}=0.1609)$, respectively. Grade 3 adverse events that occurred in the FL-IV group were leukopenia in one patient $(3.3 \%)$, nausea/vomiting in two $(6.6 \%)$, anorexia in two $(6.6 \%)$, diarrhea in one $(3.3 \%)$, and fatigue in one $(3.3 \%)$. No grade 3 or 4 adverse events were observed in the oral group. These results suggest that the oral regimen achieved equivalent efficacy to the FL-IV regimen in patients with stage II colorectal cancer, while improving their postoperative quality of life.
\end{abstract}

Correspondence to: Dr Isao Ito, Tokai University Oiso Hospital, Department of Surgery, Gakyou 21-1, Oiso, Kanagawa 259-0198, Japan

E-mail: isaoito@is.icc.u-tokai.ac.jp

Abbreviations: ONCs, occult neoplastic cells; 5-FU, 5-fluorouracil; LV, leucovorin; UFT, tegafur/uracil; 3Y-RFS, 3-year relapse-free survival; 5Y-RFS, 5-year relapse-free survival; 5Y-OS, 5-year overall survival; CPT-11, irinotecan; L-OHP, oxaliplatin; ITCs, isolated tumor cells

Key words: colorectal cancer, adjuvant chemotherapy, 5-FU/LV, UFT, PSK (Krestin), occult neoplastic cells, isolated tumor cells

\section{Introduction}

Recent advances in surgical techniques and postoperative adjuvant therapy including chemotherapy and/or radiotherapy have markedly improved the outcome of primary colorectal cancer in Japan. Although curative resection achieves a high 5 -year survival rate of $\sim 80-85 \%$ in patients who have stage II/ Dukes' B colorectal cancer without lymph node metastasis (colon: $84.5 \pm 2.8 \%$; rectum: $79.8 \pm 4.0 \%$ ) (1-3), the remaining $15-20 \%$ of patients suffer from life-threatening distant metastasis/recurrence $(2,3)$. It is thought that fatal hematogenous metastasis/recurrence affecting the liver or lungs in patients who have undergone curative resection develops when circulating cancer cells escape from immune surveillance during the perioperative period and survive to proliferate in the microenvironment of the distant organ (4-6). In particular, cytokeratin-positive occult neoplastic cells (ONCs) floating in the sinuses of lymph nodes distant from the primary tumor have been reported to show a close relationship with cancer metastasis/recurrence (7-11).

ONCs are a small number of malignant cells that become trapped in the lymph nodes which are a vital part of the immune mechanism, and can be semiquantitatively assessed by immunohistochemistry $(5,6,12)$. ONCs have been detected in $>80 \%$ of patients with recurrence after curative resection of stage II/III colorectal cancer. In patients who have stage III cancer with lymph node metastasis, ONCs often combine to form ONC clusters ( $\leq 10$ cells) or malignant microaggregates ( $>10$ cells) $\sim 0.2 \mathrm{~mm}$ in diameter, which should be distinguished from isolated tumor cells (ITC $\leq 0.2 \mathrm{~mm}$ ) or micro-metastases $(0.2 \mathrm{~mm}$ to $\leq 2 \mathrm{~mm})$ anchored in the lymph nodes (13), and are considered to represent occult systemic metastasis (14-16). It is therefore considered very important to eliminate these circulating clusters or aggregates of cancer cells during the perioperative period (14-16).

On the other hand, the NSABP-C06 study reported that standard intravenous 5-FU/LV therapy and oral 5-FU/LV therapy (UFT/UZEL; Taiho Pharmaceutical, Tokyo, Japan) 
A) FL-IV group: 5-FU/LV

5 consecutive days (1-5) per week / month / 1 course

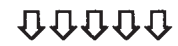

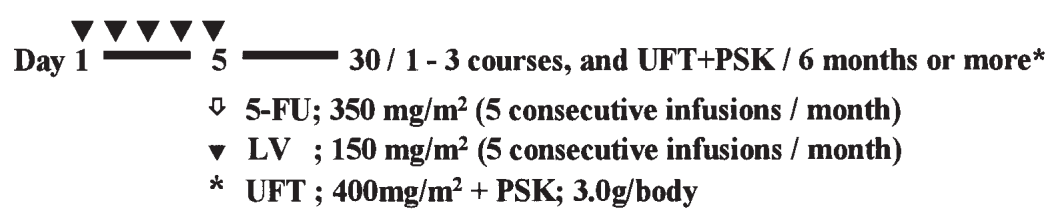

B) Oral group: UFT/PSK

5 consecutive days (1-5) on/week end off per week / month / 1 course $x 6$ months

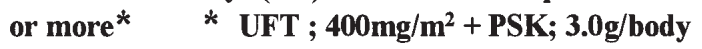

Figure 1. Schedules for postoperative adjuvant immunochemotherapy. The modified Machover regimen $\left(350 \mathrm{mg} / \mathrm{m}^{2} \mathrm{of} 5-\mathrm{FU}+150 \mathrm{mg} / \mathrm{m}^{2}\right.$ of $\mathrm{LV}$ on 5 consecutive days per month for at least $1-3$ courses postoperatively) was followed by oral UFT/PSK (A; FL-IV group). Oral UFT/PSK was given on 5 consecutive days weekly for at least 6 months without intravenous 5FU/LV (B; Oral group, UFT at $400 \mathrm{mg} / \mathrm{m}^{2}+\mathrm{PSK}$ at $3.0 \mathrm{~g}$ ).

showed almost equivalent efficacy for stage II colorectal cancer without lymph node metastasis, a result that has focused attention on oral fluoropyrimidines in the USA and Europe (17-19). Since the 1990s, oral fluoropyrimidines have been used for the outpatient treatment of most patients who receive intravenous fluoropyrimidines after surgery for stage III/ Dukes' C colorectal cancer or who undergo resection of stage II/Dukes' B colorectal cancer in Japan $(20,21)$. An oral immunochemotherapy regimen, in which oral fluoropyrimidines are combined with an oral biological response modifier (PSK, Kureha Chemical Industry, Tokyo, Japan), is also now widely used (22-29). This oral immunomodulator does not directly increase the response to 5-FU, but is intended to enhance general immunocompetence. Although good efficacy of PSK has been reported in many studies, it has not been approved in the USA and Europe (22-29).

There have been no previous studies on the comparison of high-dose 5-FU/LV via intravenous infusion with oral UFT/PSK in Japanese patients who have undergone curative resection of stage II/Dukes' B colorectal cancer. The present study was designed to compare the clinical outcome and adverse events between the above intravenous and oral regimens as postoperative adjuvant immunochemotherapy for curatively resected stage II colorectal cancer.

\section{Patients and methods}

Among 138 patients with primary colorectal cancer who underwent curative resection from 1995 to 2005, 107 patients who had stage II colorectal cancer without pathological lymph node metastasis and met the following criteria were investigated: 1) an age of 75 years or younger and a PS of 0 or 1; and 2) availability of accurate and complete medical records, as well as completed follow-up to assess recurrence and survival. They included 30 patients treated with intravenous high-dose 5-FU/LV (FL-IV group) and 77 patients treated with oral UFT/PSK alone (oral group). The FL-IV group received the modified Machover regimen, in which high-dose 5-FU (350 mg/m²) and high-dose LV $\left(150 \mathrm{mg} / \mathrm{m}^{2}\right)$ were given on 5 consecutive days per month for 1-3 courses, followed by oral administration of UFT $\left(400 \mathrm{mg} / \mathrm{m}^{2}\right)$ and
PSK (3.0 g) on 5 consecutive days weekly for 6 months or more (Fig. 1) (22,30). Patients in the oral group only received UFT $\left(400 \mathrm{mg} / \mathrm{m}^{2}\right)$ and PSK $(3.0 \mathrm{~g})$ on 5 consecutive days weekly for 6 months or more, with no postoperative intravenous therapy (Fig. 1) (22).

Eligibility and adverse events. The eligibility of each patient in the FL-IV group was determined by checking the treatment records entered by a physician or nurse in the medical record. Patients who had received 1-3 courses of the intravenous regimen were considered to be eligible. The total number and mean number of courses given were calculated. The eligibility of each patient in the oral group was confirmed by checking the treatment recorded by a physician or nurse in the medical record and from the results of a drug compliance questionnaire. Patients who suspended drug treatment for one month or longer were excluded, and those who were confirmed to have shown compliance for at least 6 months were considered to be eligible. The total number of years of treatment and the mean treatment period were calculated. All of the patients were examined for distant metastasis/ recurrence at intervals of $\sim 3$ months from 3 months postoperatively. Clinical relapse was defined as the detection of one or more metastatic lesions by both ultrasonography and computed tomography.

Then the 3-year relapse-free survival rate (3Y-RFS), 5-year relapse-free survival rate (5Y-RFS), and 5-year overall survival rate (5Y-OS) were calculated retrospectively and compared between the groups. To assess adverse events, all of the hematological and non-hematological toxicities observed after completion of 1-3 courses in the FL-IV group or from one to three months after the start of treatment in the oral group were graded retrospectively according to the Japan Clinical Oncology Group/Japanese Society of Clinical Oncology Criteria (JCOG/JSCO-CTCAE, version 3.0) and the results were compared between the groups.

Statistical analysis. The 3-year relapse-free survival rate, 5 -year relapse-free survival rate, and 5-year overall survival rate were calculated by the Kaplan-Meier method and the log-rank test was used for comparisons between the groups. 


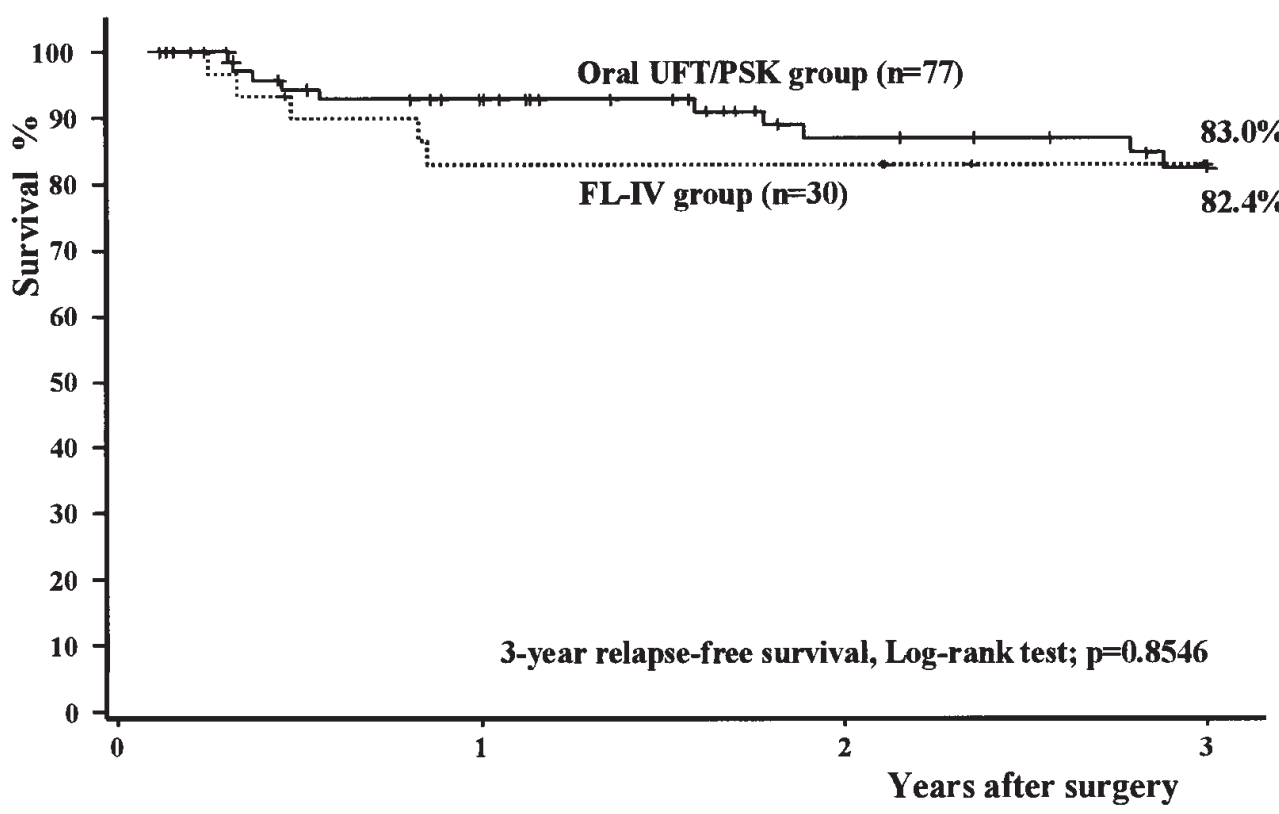

Figure 2. Three-year relapse-free survival rate of 107 patients with stage II colorectal cancer. Comparison between the intravenous 5-FU/LV (FL-IV) group and the oral UFT/PSK (oral) group. The rate was $82.4 \%$ for the FL-IV group $(\mathrm{n}=30)$ and $83.0 \%$ for the oral group $(\mathrm{n}=77)(\mathrm{p}=0.8546)$.

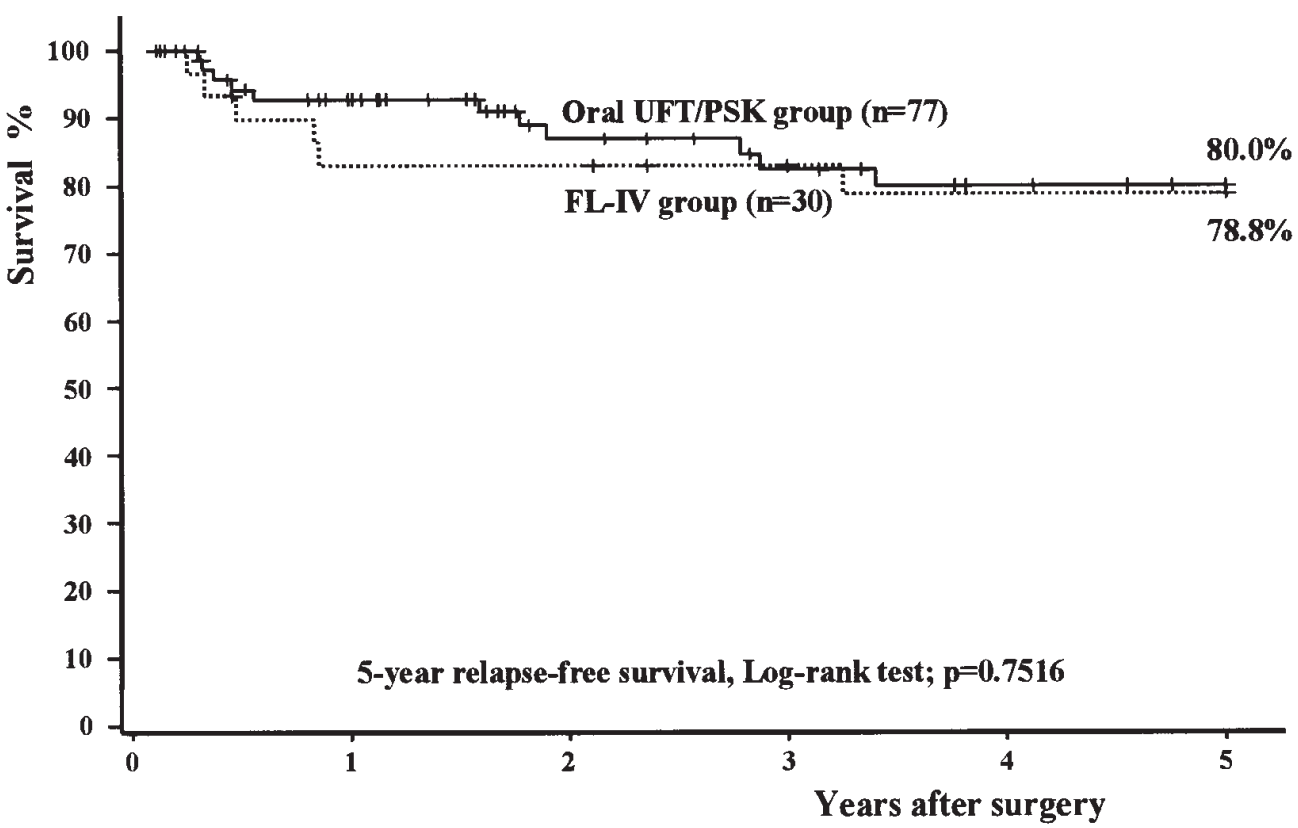

Figure 3. Five-year relapse-free survival rate of 107 patients with stage II colorectal cancer. Comparison between the intravenous 5-FU/LV (FL-IV) group and the oral UFT/PSK (oral) group. The rate was $78.8 \%$ for the FL-IV group $(n=30)$ and $80.0 \%$ for the oral group $(n=77)(p=0.7516)$.

A p-value of $<0.05$ was considered to indicate a significant difference in all analyses, which were done with SPSS $13.0 \mathrm{~J}$ software (SPSS Japan, Inc., Tokyo, Japan).

\section{Results}

The total number of courses of the postoperative intravenous therapy was 72 for the 30 patients from the FL-IV group, with a mean of 2.4 courses per patient. The administration period for subsequent oral UFT/PSK therapy was less than one year in nine patients $(30.0 \%)$ and one year or longer in
21 patients $(70.0 \%)$. The total treatment period of the 30 patients was 78.9 years, with a mean treatment period of 2.6 years per patient. The administration period for the oral group was less than one year in 24 patients $(31.2 \%)$ and one year or longer in 53 patients $(68.8 \%)$. The total treatment period of the 77 patients was 156.6 years, with a mean treatment period of 2.0 years per patient. There were no significant differences between the FL-IV and oral group with respect to $3 \mathrm{Y}$-RFS, 5Y-RFS, and 5Y-OS, which were 82.4 vs. $83.0 \%$ ( $\mathrm{p}=0.8546$; Fig. 2), 78.8 vs. $80.0 \%$ (p=0.756; Fig. 3 ), and 81.6 vs. $92.8 \%$ ( $\mathrm{p}=0.1609$; Fig. 4), respectively. 


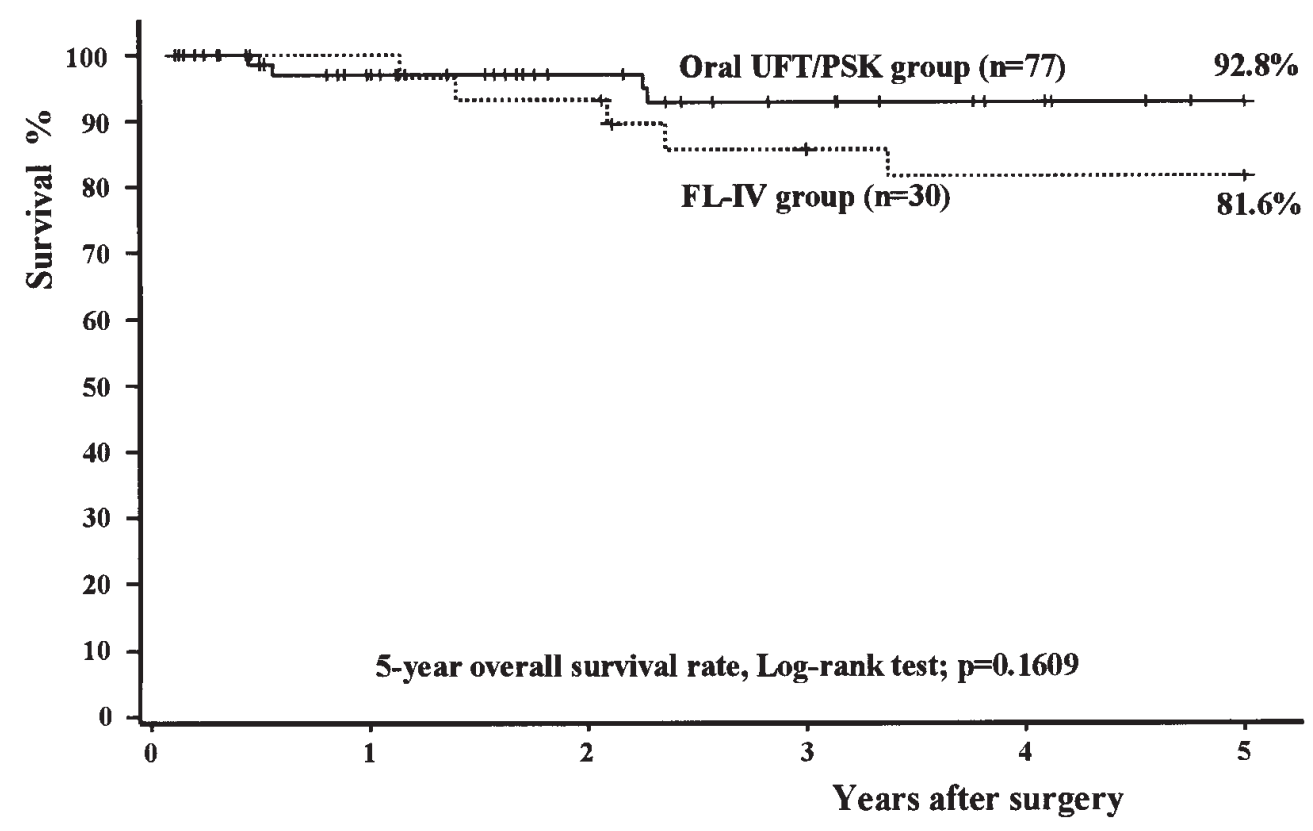

Figure 4. Five-year overall survival rate of 107 patients with stage II colorectal cancer. Comparison between the intravenous 5-FU/LV (FL-IV) group and the oral UFT/PSK (oral) group. The rate was $81.6 \%$ for the FL-IV group $(n=30)$ and $92.8 \%$ for the oral group $(n=77)(p=0.1609)$.

Table I. Grade 3 leucopenia, diarrhea, and fatigue were detected in $1 / 30$ patients $(3.3 \%)$, while Grade 3 nausea/ vomiting and anorexia occurred in $2 / 30$ patients $(6.6 \%){ }^{\mathrm{a}}$

\begin{tabular}{lccccc}
\hline Grade $(\mathrm{n}=30)$ & 1 & 2 & 3 & 4 & Grade $\leq 3$ \\
\hline Leucopenia & 4 & 2 & 1 & 0 & $1(3.3 \%)$ \\
Anemia & 3 & 1 & 0 & 0 & 0 \\
Thrombocytopenia & 0 & 0 & 0 & 0 & 0 \\
T.bil elevation & 1 & 0 & 0 & 0 & 0 \\
AST elevation & 2 & 1 & 0 & 0 & 0 \\
ALT elevation & 2 & 1 & 0 & 0 & 0 \\
\hline Nausea/vomiting & 3 & 2 & 2 & 0 & $2(6.6 \%)$ \\
Anorexia & 6 & 2 & 2 & 0 & $2(6.6 \%)$ \\
Diarrhea & 2 & 2 & 1 & 0 & $1(3.3 \%)$ \\
Fatigue & 3 & 3 & 1 & 0 & $1(3.3 \%)$ \\
Pigmentation & 2 & 1 & 0 & 0 & 0 \\
Mucositis & 3 & 1 & 0 & 0 & 0 \\
Alopechia & 1 & 0 & 0 & 0 & 0 \\
Taste abnormality & 2 & 0 & 0 & 0 & 0
\end{tabular}

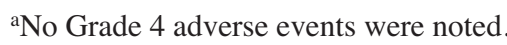

The adverse events were classified as hematological and non-hematological toxicities. The only grade 3 hematological adverse event in the FL-IV group was leukopenia in one patient $(3.3 \%$ ) (Table I). Grade 3 non-hematological adverse events in this group included nausea/vomiting in two patients $(6.6 \%)$, anorexia in two patients $(6.6 \%)$, diarrhea in one patient
Table II. The only adverse events were Grade 1 or 2 gastrointestinal symptoms, such as nausea/vomiting, anorexia, diarrhea, and fatigue. ${ }^{\text {a }}$

\begin{tabular}{llllll}
\hline Grade (n=77) & 1 & 2 & 3 & 4 & Grade $\leq 3$ \\
\hline Leucopenia & 1 & 1 & 0 & 0 & 0 \\
Anemia & 2 & 1 & 0 & 0 & 0 \\
Thrombocytopenia & 0 & 0 & 0 & 0 & 0 \\
T.bil elevation & 2 & 0 & 0 & 0 & 0 \\
AST elevation & 4 & 1 & 0 & 0 & 0 \\
ALT elevation & 4 & 1 & 0 & 0 & 0 \\
\hline Nausea/vomiting & 4 & 2 & 0 & 0 & 0 \\
Anorexia & 4 & 2 & 0 & 0 & 0 \\
Diarrhea & 2 & 2 & 0 & 0 & 0 \\
Fatigue & 2 & 2 & 0 & 0 & 0 \\
Pigmentation & 2 & 1 & 0 & 0 & 0 \\
Mucositis & 3 & 1 & 0 & 0 & 0 \\
Alopechia & 0 & 0 & 0 & 0 & 0 \\
Taste abnormality & 2 & 0 & 0 & 0 & 0 \\
\hline
\end{tabular}

${ }^{a}$ No Grade 3 or 4 adverse events were detected.

$(3.3 \%)$, and fatigue in one patient $(3.3 \%)$. Grade 4 hematological or non-hematological toxicities were not observed (Table I). In the oral group, mild gastrointestinal symptoms included Grade 1 or 2 nausea/vomiting, anorexia, diarrhea, and fatigue (3.9-7.8\%). Grade 3 or 4 adverse events were not observed in the case of either hematological or nonhematological toxicities (Table II). 


\section{Discussion}

With the recent achievement of a 5 Y-OS $>85 \%$ for Japanese patients with stage II colorectal cancer, post-operative intravenous treatment with 5 -FU has become less common since 2000. In the present study, the number of patients in the FL-IV group was only about half of that in the oral group and they were treated with the relatively popular short-term regimen of 2-3 intravenous courses. The FL-IV group tended to show slightly, but significantly, worse results than the oral group for all of the survival parameters except for 5Y-OS. The most probable cause of this difference was that the FL-IV group included a considerable number of patients who were initially diagnosed as SEI (serosal exposure and infiltration to other organs)/N0, stage IIIa cancer due to macroscopic intraoperative detection of the infiltration of organs such as the urinary bladder, small intestine, or abdominal wall, in whom the final pathological diagnoses was se (serosal exposure) $/ \mathrm{n} 0$, stage II because infiltration of other organs was not confirmed by histological examination (31). It may be considered that many patients in the FL-IV group received postoperative intravenous treatment based on the macroscopic detection of infiltration during surgery. Of the 30 patients $(16.7 \%)$ in the FL-IV group, 5 had a macroscopic diagnosis of stage IIIa (SEI/N0) cancer intraoperatively, which was histologically shown to be stage II (pathological se/n0). Two experienced recurrence and they accounted for $33.3 \%(2 / 6)$ of the patients with recurrence in the FL-IV group. There were no significant relations between tumor size, macroscopic infiltration, and recurrence. Based on the view that stage IIIa disease with histopathological tumor infiltration of other organs (sei) and no lymph node metastasis (n0) is unlikely to be an independent prognostic factor, the Japanese Rules for Handling of Cancer in the latest edition have been revised to include such patients in stage II (31).

The NSABP-C06 study reported that the oral 5-FU/oral $\mathrm{LV}$ regimen was equivalent to the intravenous $5-\mathrm{FU} / \mathrm{LV}$ regimen with respect to $5 \mathrm{Y}-\mathrm{RFS}$ and $5 \mathrm{Y}$-OS when these treatments were compared as postoperative adjuvant chemotherapy for patients with stage II colorectal cancer $(17,18)$. However, 5Y-RFS and 5Y-OS cannot be compared among different studies because there is no standard treatment for hepatic or pulmonary recurrence in each institution, no consensus about which recurrences should be treated by surgical resection, and no established therapeutic strategy for recurrent disease including second-line chemotherapy. It is therefore considered that the 3Y-RFS may more accurately indicate the control of early recurrence than the 5Y-RFS when evaluating the therapeutic efficacy of first-line adjuvant treatment during the period of $\sim 6$ months after surgery. The $3 \mathrm{Y}$-RFS of the two groups was also equivalent in the present study.

It has been reported that oral 5-FU/oral LV therapy markedly improves QOL compared with the corresponding intravenous therapy, but is still associated with frequent gastrointestinal symptoms, including mild to moderate abdominal discomfort, nausea, and anorexia (17-19). In Japan, oral LV also has the disadvantage of placing a great economic burden on patients. It has also been reported that the immunomodulatory effect of PSK is more evident in patients with stage II/NO disease, among whom dispersion of single ONCs into the portal circulation has already commenced compared to stage III patients $(20,21)$. In contrast, PSK is less expensive and causes very few adverse drug reactions, and UFT/PSK regimen could be administered for $>2$ years with a very low incidence of adverse effects and a very small number of withdrawals (22-29). Since the FL-IV and oral groups showed equivalent clinical results, it seems that oral UFT/PSK might be sufficient to eliminate circulating ONCs except for clusters $(20,21)$. Considering QOL, compliance, and medical costs, oral immunochemotherapy may be superior as first-line adjuvant therapy for stage II colorectal cancer in Japan. To eliminate ONC clusters or micro-aggregates, which may cause distant metastasis/ recurrence in $5-10 \%$ of postoperative patients with stage II cancer that is a much lower expression rate than in patients with stage III cancer (14-16), it may be necessary to carefully examine the need for intravenous consolidation chemotherapy with multiple-drug combination regimens such as IFL/ FOLFIRI/FOLFOX that employ CPT-11 (irinotecan) and/or L-OHP (oxaliplatin) in stage II patients with a high risk of recurrence/metastasis (32-34). A prospective study is now underway to evaluate patients with stage II colorectal cancer divided into high or low risk groups of cancer recurrence/ metastasis, who have undergone surgery followed by adjuvant immunochemotherapy as a single oral agent (UFT/PSK). The final results will be analyzed at the end of $2009(12,15)$.

\section{Acknowledgements}

This study was supported by grants from the Occult Neoplastic Cells Research and Study Group (\#2007-5007; Tokai University Hachioji Hospital, Tokyo, Japan) and the Research and Study Program of Tokai University Educational System General Research Organization (\#2007-04; Tokai University Hospital, Kanagawa, Japan).

\section{References}

1. Japanese Society for Cancer of the Colon and Rectum: MultiInstitutional Registry of Large Bowel Cancer in Japan, Vol. 23, Cases treated in 1994. Kanehara \& Co., Ltd., Tokyo, 2002.

2. Knacks \& Pitfalls: Surgery of the Colon, Rectum and Anus. 2nd edition. Bunkoudou \& Co., Ltd., Tokyo, 2004.

3. Japanese Society for Cancer of the Colon and Rectum: Guideline for Large Bowel Cancer in Japan. Kanehara \& Co., Ltd., Tokyo, 2005.

4. Mukai M, Ito I, Mukoyama S, Tajima T, Saito Y, Nakasaki H, Sato $\mathrm{S}$ and Makuuchi H: Improvement of 10-year survival by Japanese radical lymph node dissection in patients with Dukes' B and C colorectal cancer: A 17-year retrospective study. Oncol Rep 10: 927-934, 2003.

5. Mukai M, Sato S, Komatsu N, Nishida T, Shiba K, Ito I, Nakasaki $\mathrm{H}$ and Makuuchi $\mathrm{H}$ : Correlation between occult neoplastic cells in the lymph node sinuses and recurrence in patients with Dukes' C colorectal cancer. Oncol Rep 10: 1165-1169, 2003.

6. Mukai M, Sato S, Komatsu N, Nishida T, Shiba K, Ito I, Nakasaki $H$ and Makuuchi $H$ : Correlation between occult neoplastic cells in the lymph node sinuses and recurrence in patients with curatively resected Dukes' B colorectal cancer. Oncol Rep 10: 1177-1181, 2003.

7. Mukai M, Sato S, Nakasaki H, Saito Y, Nishiumi N, Iwasaki M, Tokuda Y, Ogoshi K, Inoue H and Makuuchi H: Occult neoplastic cells in the lymph node sinuses and recurrence of primary breast, lung, esophageal and gastric cancer. Oncol Rep 11: $81-84,2004$. 
8. Mukai M, Sato S, Komatsu N, Kimura T, Ninomiya H, Nakasaki H, Ogoshi K and Makuuchi M: Accuracy of criteria for predicting the recurrence and metastasis of stage I and II gastric cancer without lymph node metastasis. Oncol Rep 12: 59-62, 2004.

9. Mukai M, Sato S, Komatsu N, Kimura T, Ninomiya H, Nakasaki H, Ogoshi K and Makuuchi H: Accuracy of criteria for predicting recurrence and metastasis in stage II and III gastric cancer with lymph node metastasis. Oncol Rep 12: 63-66, 2004.

10. Mukai M, Sato S, Komatsu N, Kimura T, Ninomiya H, Nakasaki H, Ogoshi K and Makuuchi H: Predicting the recurrence/metastasis of stage II and III breast cancer with lymph node metastasis. Oncol Rep 12: 303-306, 2004.

11. Mukai M, Sato S, Komatsu N, Kimura T, Ninomiya H, Nakasaki H, Ogoshi K and Makuuchi H: Predicting the recurrence/metastasis of stage I and II breast cancer without lymph node metastasis. Oncol Rep 12: 745-748, 2004.

12. Mukai M, Sato S, Nishida T, Komatsu N, Shiba K, Nakasaki H, and Makuuchi $\mathrm{H}$ : Selection criteria for high risk and low risk groups of recurrence and metastasis in patients with primary colorectal cancer. Oncol Rep 10: 1753-1758, 2003.

13. TNM Classification of Malignant Tumours. 6th edition, John Wiley \& Sons, Inc., New York, 2002.

14. Mukai M: Occult neoplastic cells and malignant micro-aggregates in lymph node sinuses: Review and hypothesis. Oncol Rep 14: 173-175, 2005.

15. Mukai M, Sato S, Ninomiya H, Wakui K, Komatsu N, Tsuchiya K, Tajima T, Nakasaki H and Makuuchi H: Prospective study on the recurrence/metastasis of stage II/III colorectal and gastric cancer associated with occult neoplastic cells in lymph node sinuses: Three-year interim results. Oncol Rep 16: 405-410, 2006.

16. Mukai M, Oida Y, Tajima T, Kishima K, Ninomiya H, Sato S, Nakamura M, Nakasaki $\mathrm{H}$ and Makuuchi H: Alternating hepatic arterial infusion and systemic chemotherapy for stage IV colorectal cancer with synchronous liver metastasis. Oncol Rep 16: 865-870, 2006.

17. Mukai M, Moriya H, Himeno S, Oida Y, Mukoyama S, Nishi T, Nakasaki H, Sato S and Makuuchi H: Efficacy of oral UFT plus leucovorin therapy for colon cancer with ovarian and multiple liver metastases: Report of two cases. Oncol Rep 8: 1079-1083, 2001.

18. Wolmark N, Wieand S, Lembersky B, Colangelo L, Smith R and Pazdur R: A phase III trial comparing oral UFT to FULV in stage II and III carcinoma of the colon: Results of NSABP protocol C-06. Proc Am Soc Clin Oncol 22 (14S): 247s, \#358, 2004.

19. Lembersky BC, Wieand HS, Petrelli NJ, O'Connell MJ, Colangelo LH, Smith RE, Seay TE, Giguere JK, Marshall ME, Jacobs AD, Colman LK, Soran A, Yothers G and Wolmark N: Oral uracil and tegafur plus leucovorin compared with intravenous fluorouracil and leucovorin in stage II and III carcinoma of the colon: results from National Surgical Adjuvant Breast and Bowel Project Protocol C-06. J Clin Oncol 24: 2059-64, 2006.

20. Mukai M, Tajima T, Nakasaki H, Sato S, Ogoshi K and Makuuchi H: Efficacy of postoperative adjuvant oral immunochemotherapy in patients with Dukes' B colorectal cancer. Ann Cancer Res Therap 11: 201-214, 2003.

21. Mukai M, Tajima T, Nakasaki H, Sato S, Ogoshi K and Makuuchi H: Efficacy of postoperative adjuvant oral immunochemotherapy in patients with Dukes' C colorectal cancer. Ann Cancer Res Therap 11: 215-229, 2003.

22. Mukai M, Tokunaga N, Yasuda S, Mukoyama S, Itoh I, Kameya T, Ishikawa K, Iwase H, Suzuki T, Ishida H, Sadahiro S and Makukuchi H: Long-term survival after immunochemotherapy in a patient of juvenile colon cancer with peritoneal dissemination: A case report. Oncol Rep 7: 1343-1347, 2000.
23. Mitomi T, Tsuchiya S, Iijima N, Aso K, Suzuki K, Nishiyama K, Amano T, Takahashi T, Murayama N, Oka H, Oya K, Noto T and Ogawa N: Randomized controlled study on adjuvant immnochemotherapy with PSK in curatively resected colorectal cancer. The Cooperative Study Group of Surgical Adjuvant Immunochemotherapy for Cancer of the Colon and Rectum (Kanagawa). Dis Colon Rectum 35: 123-130, 1992.

24. Nakazato H, Koike A, Saji S, Ogawa N and Sakamoto J: Efficacy of immunochemotherapy as adjuvant treatment after curative resection of gastric cancer. Lancet 33: 1122-1126, 1994.

25. Sakamoto J, Hamada C, Kodaira S, Nakazato H and Ohashi Y: Adjuvant therapy with oral fluoropyrimidines as main chemotherapeutic agents after curative resection for colorectal cancer: individual patient data meta-analysis of randomized trials. Jpn J Clin Oncol 29: 78-86, 1999.

26. Munemoto Y, Iida Y, Abe J, Saito H, Fujisawa K, Kasahara Y, Mitsui T, Asada Y and Miura S: Significance of postoperative adjuvant immunochemotherapy after curative resection of colorectal cancers: Association between host or tumor factors and survival. Int J Oncol 20: 403-411, 2002.

27. Koda K, Miyazaki M, Sarashina H, Suwa T, Saito N, Suzuki M, Ogawa K, Watanabe S, Kodaira S and Nakazato H: A randomized controlled trial of postoperative adjuvant immunochemotherapy for colorectal cancer with oral medicines. Int J Oncol 23: 165172,2003

28. Ohwada S, Ikeya T, Yokomori T, Kusaba T, Roppongi T, Takahashi T, Nakamura S, Kakinuma S, Iwazaki S, Ishikawa H, Kawate S, Nakajima T and Morishita Y: Adjuvant immunochemotherapy with oral Tegafur/Uracil plus PSK in patients with stage II or III colorectal cancer. Br J Cancer 90: 1003-1010, 2004.

29. Sakamoto J, Morita J, Oba K, Matsui T, Kobayashi M, Nakazato $\mathrm{H}$ and Ohashi Y: Efficacy of adjuvant immunochemotherapy with polysaccharide $\mathrm{K}$ for patients with curatively resected colorectal cancer: A meta-anlysis of centrally randomized controlled clinical trials. Cancer Immunol Immunother 55: 404-411, 2006.

30. Machover D, Schwarzenberg L, Goldschmidt E, Tourani JM, Michalski B, Hayat M, Dorval T, Misset JL, Jasmin C, Maral R and Mathe G: Treatment of advanced colorectal and gastric adenocarcinomas with 5-FU combined with high-dose folinic acid: a pilot study. Cancer Treat Rep 66: 1803-1807, 1982.

31. General Rules for Clinical and Pathological Studies on Cancer of the Colon, Rectum and Anus. Japanese Society for Cancer of the Colon and Rectum. 7th edition, Kanehara \& Co., Ltd., Tokyo, 2006.

32. Saltz LB, Cox JV, Blanke C, Rosen LS, Fehrenbacher L, Moore MJ, Maroun JA, Ackland SP, Locker PK, Pirotta N, Elfring GL and Miller L, for the Irinotecan study group: Irinotecan plus fluorouracil and leucovorin for metastatic colorectal cancer. N Engl J Med 343: 905-914, 2000.

33. Tournigand C, Achille TAE, Lledo G, Flesh M, Quinaux DM-ME, Couteau C, Buyse M, Ganem G, Landi B, Colin P, Louvet C and De Gramont A: FOLFIRI followed by FOLFOX 6 or the reverse sequence in advanced colorectal cancer: A randomized GERCOR study. J Clin Oncol 22: 229-237, 2004.

34. Colucci G, Gebbia V, Paoletti G, Giuliani F, Caruso M, Gebbia N, Carten G, Agostara B, Pezzella G, Manzione L, Borsellino N, Misino A, Romito S, Durini E, Cordio S, Seri MD, Lopez M and Maiello E: Phase III randomized trial of FOLFIRI versus FOLFOX 4 in the treatment of advanced colorectal cancer: A multicenter study of Gruppo Oncologico Dell'Italia Meridionale. J Clin Oncol 23: 4866-4875, 2005. 